\title{
Different Recipes and Energy Density of Indonesia Fast Food on Percentage of Indonesian Daily Value
}

\author{
Widya Rahmawati and Dian Handayani* \\ Department of Nutrition, Faculty of Medicine, University of Brawijaya, Malang, Indonesia 65145
}

Received: 21 May, 2014; Accepted: 18 June, 2014; Published: 20 June, 2014

*Corresponding author: Dian Handayani, PhD, Department of Nutrition, Faculty of Medicine, University of Brawijaya, Malang, Indonesia 65145, Tel: 62341 567192, 569117 Ext 133; Fax: 62341 564755; Email : handayani_dian74@yahoo.com.au or handayani_dian@ub.ac.id

\begin{abstract}
The increment of fast food consumption and lack of knowledge about balanced food are leading to excessive energy intake and excessive body weight. This cross-sectional study aimed to compare Energy density (ED) and contribution to \% Indonesian Daily Value (DV) of fast food cooked based on Indonesian traditional recipe (INA, $n$ 39), food cooked based on Oriental recipe (ORI, n 11) and food cooked based on Western recipe (WEST, n 22) in Malang City, Indonesia. Energy and nutrient analysis was performed using NutriSurvey 2007. Statistical analysis was performed using SPSS 17 (Statistical Package for the Social Sciences). This present study showed that energy, protein, dietary fiber and cholesterol contents per serving were similar among three groups. Majority of food contributed to $26-39 \%$ of energy DV, $33-54 \%$ of protein DV and $7-17 \%$ of dietary fiber DV. ED of INA and ORI foods $(1.47 \pm 0.09 \mathrm{kcal} / \mathrm{g}$ vs $1.66 \pm 0.34$ $\mathrm{kcal} / \mathrm{g}$, respectively) was significantly lower than that of WEST food $(2.46 \pm 0.21 \mathrm{kcal} / \mathrm{g})(\mathrm{P}<0.05)$. ED was correlated with total weight, water, energy, fat and cholesterol content per portion. In conclusion, Indonesian traditional and Oriental food had high volume and lowenergy-density. The information related nutritional content of food is important for community. It can be used for considering food choices to meet its dietary recommendation for combating obesity.
\end{abstract}

Keywords: Energy density; Portion; Weight food; Indonesian fast food

\section{Energy Density of Indonesian Fast Food Based on Indonesian Traditional, Oriental and Western Recipes}

Excess of body weight is a rapid-growing public health problem in the world. It is a chronic disease that promotes metabolic syndrome and one of the leading global risks for morbidity and mortality globally. ${ }^{[1,2]}$ It is an important risk factor for several causes of death including cardiovascular disease, stroke, diabetes, and cancer. Globally, overweight and obesity attributed to about 3\% disability-adjusted life years (DALYs) and 3 million deaths annually. ${ }^{[2,4]}$ The prevalence of overweight and obesity has increased globally in three last decades ${ }^{[4]}$, included in Indonesia. Prevalence of overweight (BMI $>25 \mathrm{~kg} / \mathrm{m}^{2}$ ) in Indonesia was increased from $13.9 \%-14.8 \%$ in 2007 to $19.7 \%$ $32.9 \%$ in 2013. ${ }^{[5]}$

Low level of knowledge about nutrition and balanced food, unhealthy dietary pattern, and sedentary activity were assumed as the main contributing factors for the increment of overweight and obesity in Indonesia. ${ }^{[6]}$ Properties of food, such as large portion of high-energy-dense food has strong effect on excessive consumption, especially if it happened in long period. ${ }^{[7]}$ The changes of food intake in middle-income country can be affected by availability of multinational fast food outlets. ${ }^{[8]}$ Eating environment such as ready availability of palatable large portion of high-energy dense food can override the excess of energy intake over prolonged periods. ${ }^{[7,9]}$ Previous study showed the correlation between energy density, low fiber, and high dietary fat pattern and increased fatness in childhood ${ }^{[10]}$ and in adult. ${ }^{[9,11]}$

There is a trend in Indonesian people to shift their food pattern from traditional into high fat and low fiber fast food. ${ }^{[6]}$ Fast food outlet in Indonesia includes fast food cooked based on Indonesian traditional recipe or adopted from multinational recipe.

This study aims to compare energy density of food cooked based Indonesian traditional recipe, food cooked based on Oriental recipe and food cooked based on Western recipe and to compare the contribution of 1 serving size of food to \% Daily Value (DV) of Indonesian people that around $2000 \mathrm{kcal} /$ day, in order to provide valuable information for community.

\section{Methods}

\section{Study methods and materials}

A cross sectional study was conducted from June to December 2013 among seventy two menus of fast foods from the most popular fast food restaurants in Malang City, Indonesia. Fast food included in this study is main meal that is usually chosen by customers as breakfast, lunch or dinner food. Fast food was grouped into fast food cooked based on Indonesian traditional recipe (INA, $n$ 39), fast food cooked based on Oriental recipe (ORI, $n$ 11) and fast food cooked based on Western recipe (WEST, $n$ 22).

\section{Procedures}

Energy and nutrient content analyses: Weight per serving was measured using oxone digital food scale type OX-315 with 1 
g sensitivity. Energy and nutrient (protein, fat, carbohydrate and dietary fiber) content analysis was performed using Nutrisurvey for Windows version 2007 with Indonesian food data base. ${ }^{[12]}$ Water content per serving derived from calculation of: Weight per serving $=$ total weight - (weight of carbohydrate + protein + fat + fiber).

Energy density was calculated using the formula: ED = the amount of energy (kcal) / weight of food (g). ${ }^{[13,14]}$ ED thus categorized as low ED $(<1.5 \mathrm{kcal} / \mathrm{g})$, medium ED (1.5-2.25 kcal $/ \mathrm{g})$ and high ED (> $2.25 \mathrm{kcal} / \mathrm{g})^{[15]}$ Contribution of 1 serving size of food to \% DV based on $2000 \mathrm{kcal}$, protein 60 grams, fats 67 grams, carbohydrate 275 grams, dietary fiber 28 grams, and cholesterol $300 \mathrm{mg}$. ${ }^{[16,17]}$

Statistical analyses: Statistical analyses were performed using SPSS $17^{\text {th }}$ for window. Desciptive analyses were carried out to characterize energy and nutrient content among foods.
Kolmogorov-Smirnov normality test was used to check the normality of data distribution. Normally distributed data was presented as mean $\pm S D$, while not normally distributed data was presented as median and interquartile range.

One way Anova test and Post Hoc Tukey were used to examine differences in means among three food goups for normally distributed data. While the Kruskall Wallis (continued by Mann Whitney test) was used to examine differences in median among three food goups for non-normally distributed data. Spearman Rank test was used to examine the correlation between ED and other variables.

\section{Results}

This present study showed that energy, protein, fat, dietary fiber and cholesterol content per serving was similar among three fast food groups. Total weight and water content of INA

Table 1: General Characteristics of Indonesian fast food.

\begin{tabular}{|c|c|c|c|c|}
\hline & $\begin{array}{l}\text { INA Food } \\
\text { (n 39) }\end{array}$ & $\begin{array}{l}\text { ORI Food } \\
\text { (n 11) }\end{array}$ & $\begin{array}{l}\text { WEST Food } \\
\text { (n 22) }\end{array}$ & $\begin{array}{c}\text { All } \\
(n 72)\end{array}$ \\
\hline Weight per serving $(g)^{+, \S}$ & $435.0(181.0)$ & $369.0(363.0)$ & $327.5(174.5)$ & $367.0(181.5)^{* *}$ \\
\hline Water $(\mathrm{g})^{+, \delta, \text { 回 }}$ & 325.5 (166.9) & $231.7(311.1)$ & $142.4(145.5)$ & $242.6(209.5)^{* *}$ \\
\hline Energy $(\mathrm{kcal})^{\dagger}$ & $608.3(232.6)$ & $541.6(298.8)$ & $730.5(435.5)$ & $630.1(259.5)$ \\
\hline $\operatorname{Protein}(\mathrm{g})^{\dagger}$ & $23.7(10.7)$ & $27.6(12.3)$ & $27.9(25.9)$ & $26.6(12.4)$ \\
\hline Carbohydrate $(\mathrm{g})^{\ddagger \S, \pi}$ & $71.93(27.8)$ & $49.3(31.8)$ & $56.6(26.9)$ & $63.8(29.2)^{*}$ \\
\hline Fat $(\mathrm{g})^{+, \S}$ & $27.8(18.0)$ & $32.3(26.3)$ & $40.0(36.9)$ & $31.6(24.2)^{*}$ \\
\hline Dietary Fiber $(\mathrm{g})^{+}$ & $2.5(3.0)$ & $2.1(1.3)$ & $4.2(4.2)$ & $3.1(2.9)$ \\
\hline Cholesterol (mg) ${ }^{\dagger}$ & $59.3(73.5)$ & $235.2(259.6)$ & 55.7 (57.5) & $63.2(123.1)$ \\
\hline
\end{tabular}

${ }^{\dagger}$ Data presented in Median (interquartile range) for non normally-distributed data; $P$ values were calculated using Kruskall-Wallis and Mann-Whitney $U$ Test

${ }^{*}$ Data presented in Mean (standard deviation) for normally-distributed data, $P$ values were calculated using Oneway ANOVA Test

${ }^{*} P<0.05,{ }^{* *} P<0.01$ for value difference between food groups

§Significant different between INA and WEST food

Significant different between ORI and WEST food

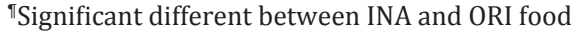

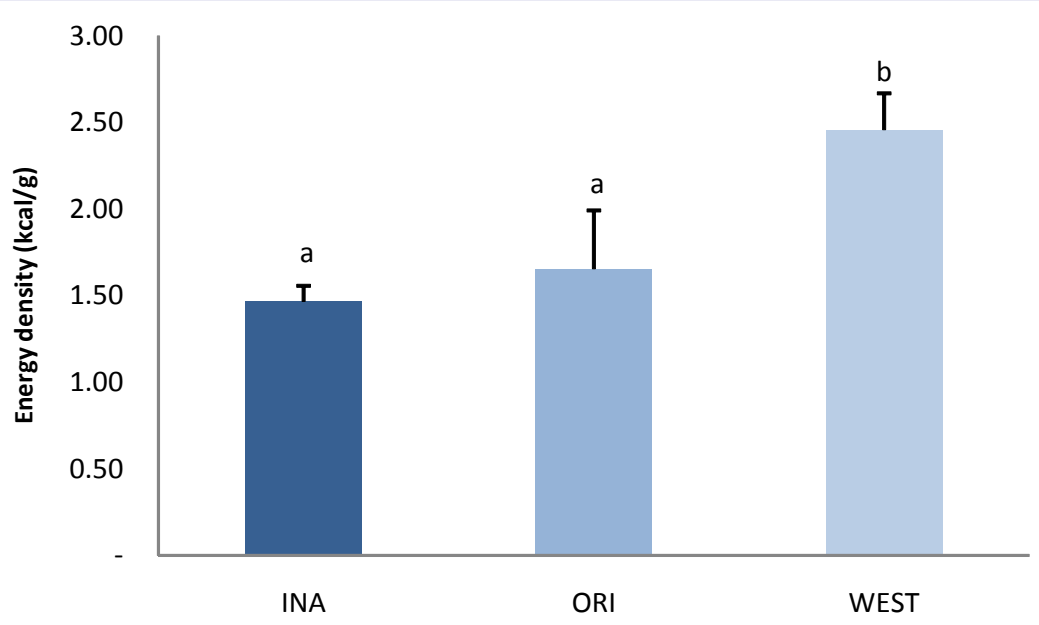

Figure 1: Comparison of energy density among three fast food groups ${ }^{\dagger,}$

†Bars represent median and interquartile range.

*The different superscript (a,b) are mean significantly different $(P<0.05) ; P$ values were calculated using Mann-Whitney $U$ Test. 
and ORI food was significantly higher than those of WEST food. Carbohydrate of INA food was significantly higher than those of ORI food, but similar with those of WEST food Table 1.

ED of INA and ORI foods $(1.47 \pm 0.09 \mathrm{kcal} / \mathrm{g}$ vs $1.66 \pm 0.34$ $\mathrm{kcal} / \mathrm{g}$, respectively) was significantly lower than those in WEST food (2.46 $\pm 0.21 \mathrm{kcal} / \mathrm{g}$, respectively) Figure 1 . About $60 \%$ of INA and $45 \%$ ORI food was categorized as low ED. Only $14 \%$ of WEST food was categorized as low ED. More than half of WEST food was grouped high ED Figure 2.

ED of INA food was correlated with total weight, water, energy and fat content per portion. ED of ORI food was correlated with weight and water content per portion. ED of WEST food was correlated with energy content per portion. Overall, ED was correlated with total weight, water, energy, fat and cholesterol content per portion $(r=-0.702,-0.816,0.370,0.521,0.313$, respectively; $\mathrm{P}<0.05$ ) Table 2 .

This study found that majority of fast food contributed to 26$39 \%$ of energy DV, 33-54\% of Protein DV, 7-17\% of dietary fiber DV and $13-55 \%$ of maximum recommended for cholesterol DV, and there was no difference among three groups. Contribution of WEST food to \% fat DV was significantly higher than that of INA food $(59.7 \%$ vs $41.5 \%, P=0.011)$, and it was similar with ORI food (48.2\%). Contribution of INA food to \% carbohydrate DV was significantly higher than those of ORI food $(27.4 \%$ vs $14.3 \%$, $P=0.015)$, but it was similar with WEST food (19.6\%) Figure III.

\section{Discussion}

Although total energy of one serving size of three food groups was similar, Indonesian traditional recipe-based fast food (INA) and Oriental recipe-based fast food (ORI) have lower Energy Density (ED) than those of Western recipe-based fast food (WEST). The majority of INA and ORI food were categorized as low or medium ED, while more than half of WEST food were categorized into high ED.

ED of food in this study was correlated with water content in food. INA and ORI food had lower ED than WEST food because they had high content of water. Majority INA and ORI food that had low ED also had also large portion brooth based soup. The example of INA food that had low ED and large portion of water content such as chicken soup (sop ayam, soto ayam), vegetable soup (sayur asam), rice porridge (bubur ayam) while the example of ORI food that had low ED and high water content were sapo tofu, cap jae (mixed sauteed vegetables).

These result were in line with previous study that showed that traditional Asian foods usually have low ED. There is low ED in Asian foods because they are processed by boiling or steaming than frying ${ }^{[18]}$ Water has the greatest factor that influences ED

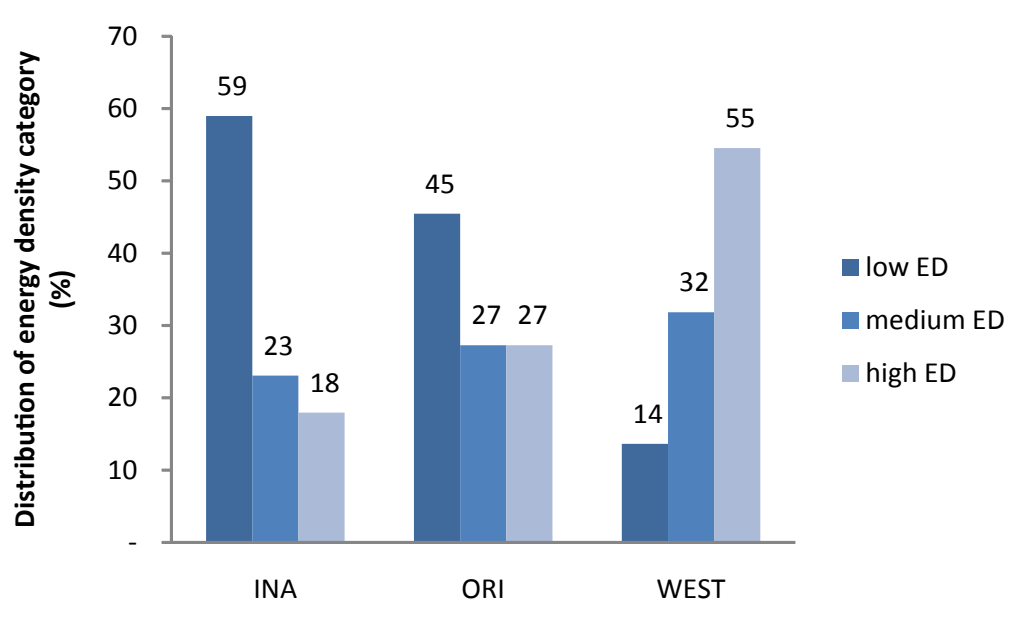

Figure 2: Distribution of energy density category among three fast food groups.

Table 2: Corelation between Energy Density and other variables.

\begin{tabular}{|c|c|c|c|c|}
\hline & \multicolumn{4}{|c|}{ Spearman's rho Correlation Coefficient } \\
\hline & INA & ORI & WEST & All \\
\hline Weight per serving (g) & $-0.838^{* * *}$ & $-0.821^{*}$ & -0.109 & $-0.702^{* * *}$ \\
\hline Water (g) & $-0.924^{* * *}$ & $-0.821^{*}$ & -0.406 & $-0.816^{* * *}$ \\
\hline Energy (kcal) & $0.390^{*}$ & 0.214 & $0.509^{*}$ & $0.370^{* *}$ \\
\hline Protein (g) & -0.068 & -0.179 & 0.388 & 0.168 \\
\hline Fat (g) & $0.456^{*}$ & 0.607 & 0.424 & $0.521^{* * *}$ \\
\hline Carbohydrate (g) & -0.114 & -0.214 & 0.503 & -0.255 \\
\hline Dietary fiber (g) & 0.026 & -0.429 & -0.379 & -0.085 \\
\hline Choleserol (mg) & 0.247 & -0.107 & 0.429 & $0.313^{*}$ \\
\hline
\end{tabular}

${ }^{*} P<0.05,{ }^{* *} P<0.01,{ }^{* * *} P<0.001 ; P$ values were calculated using Spearman Rank Correlation Test. 


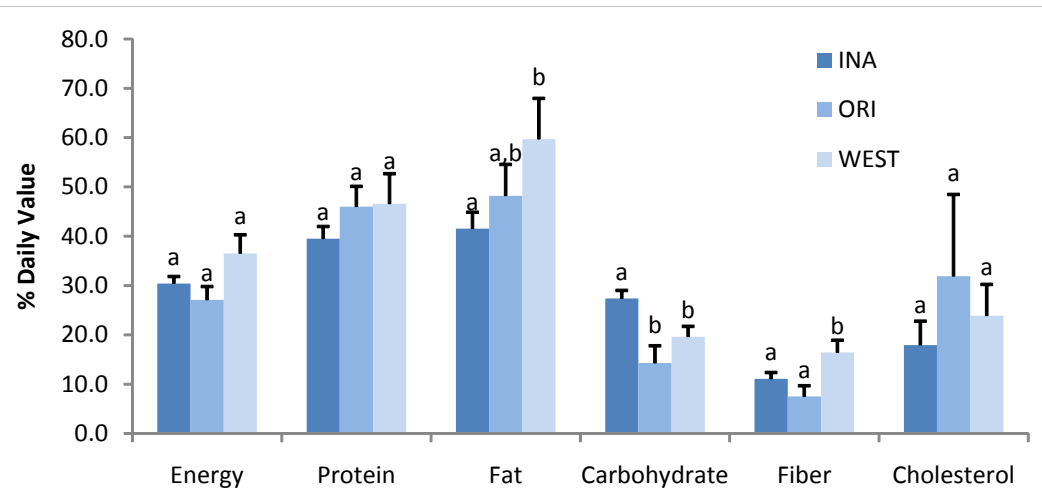

Figure 3: Contribution of 1 serving size of food to \% Daily Value (DV)

${ }^{\dagger}$ Bars represent median and interquartile range.

*The different superscript $(\mathrm{a}, \mathrm{b})$ are mean significantly different $(P<0.05) ; \quad P$ values were calculated using Mann-Whitney $U$ Test.

since it adds substantial weight without adding any energy. ${ }^{[19]}$ High content of water decreases ED, even high-fat foods, because water contributes to weight and volume of food but without providing additional energy. ${ }^{[11]}$ On the other hand, the main source of food served in Asia food is rice or grain group. These groups were reported to tend the bulky of serving with low in energy density. ${ }^{[18,20]}$

There was a trend that low-energy-dense of WEST food in this study are included in foods with large portion of salad. Serving more vegetables in meal is an effective strategy to increase dietary fiber intake ${ }^{[21]}$ and reduce energy intake. ${ }^{[22,19]}$ Combination between high vegetables and low fat content of food is an effective strategy for managing body weight while controlling hunger. ${ }^{[23]}$

This study found that ED was correlated with the fat content of foods. There was also a trend that all high ED food groups IS OF high fat content, low fiber and limit water content of food. Previous study found that the applying of fat increase total energy content per serving thus the ED was higher than other nutrients.

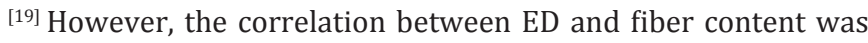
not revealed in this study. It could result from dietary fiber content among three food groups that were similar and the fiber content of the foods were limited.

This study found that Indonesian traditional foods had higher volume and lower ED than Western food. The previous study showed that people are likely to eat constant volume of food. Reduction of ED was associated with spontaneus decrease in daily energy intake. ${ }^{[13]}$ In contrast, increase of ED will be associated with spontaneus increase in daily energy intake. Energy intake of Indonesian people with high volume of food with low ED consumption habit will spontaneusly increase if they shifts their food choice from traditional Indonesian low-energy dense food into western high-energy-dense food.

One portion of Indonesian fast food from three groups contributed to about one third of energy DV (DV=2000 kcal / day). ${ }^{[17]}$ INA food, like others Asian foods, has rice as the most important staple food. ${ }^{[20]}$ Part of Indonesian people had strong perception regarding their dietary behaviour that main meals must include rice as staple food, and this perception is difficult to be changed. ${ }^{[24]}$ Main meals subtitution without rice -such as noodle, meatball soup, burger, and pizza- was not considered main meals but as snack by half of Indonesian. Consumption of fast food without rice that is perceived as snack will increase double energy intake because they will also consume another meals with rice to fullfill their 'perceived need' for main meal. Another hand, WEST food had significantly higher contribution to fat DV of Indonesian than INA food. Consumption of WEST food twice a day will contribute to more than $100 \%$ DV of Indonesian. Previous study found that foods that contain fat were more palatable, and the most likely target of food craving are those food that contain fat beside sugar or both. ${ }^{[25]}$ High-fat Western dietary pattern was associated with increased of cancer risk. ${ }^{[18]}$

One portion of INA food was about $10 \%$ of dietary fiber Daily Value (DV), while one portion of WEST food contributed to $19 \%$ of dietary fiber DV. This finding was inline with previous Indonesia Ministry of Health survey that showed only about $6,4 \%$ of Indonesian people consumed adequate dietary fiber. Although Indonesia is rich of vegetables and fruits, unfortunately, preference of Indonesian people to consume a high dietary fiber such as mixed vegetables with peanut sauce (gado-gado, pecel, karedok), and mixed vegetables with rasped coconut seasoning (urap-urap) was low. ${ }^{[6]}$ The consumption of dietary fiber among other Asian country was also relatively low in impoverished communities, and often high in those that are more prosperous ${ }^{[18]}$ Consumption of dietary fiber needs promoting. ${ }^{[6]}$

\section{Conclusion}

Indonesian traditional and Oriental food had higher volume and lower-energy-density than those of Western food. One portion of Indonesia fast food from three groups contributed to about one third of \% energy DV. The information related nutritional content of food is important for community. It can be used for considering food choices to meet its dietary recommendation for combating obesity.

\section{Acknowledgements}

We thank to all fast food restaurants who participated in this study. There is no conflict of interest. 


\section{References}

1. Anapaula CB Rizzo, Tamara BL Goldberg, Carla C Silva, Cilmery S Kurokawa, Helio RC Nunes, José E Corrente. Metabolic syndrome risk factors in overweight, obese, and extremely obese Brazilian adolescents. Nutrition Journal2013;12(19):1-7.

2. World Health Organization. Global health risk: mortality and burden of disease attributable to selected major risk. Geneva: World Health Organization,2009.

3. Whitlock G, Lewington S, Sherliker $P$ et al. Body-mass index and cause-specific mortality in 900000 adults: collaborative analyses of 57 prospective studies. Lancet2009;373(9669):1083-1096.

4. Stevens G, Singh G, Lu Y et al. National, regional, and global trends in adult overweight and obesity prevalences. Population Health Metrics2012;10:22

5. Research and Development Department - MOH RI. Presentation of Helath Result of Indonesia Basic Health Reserach 2013.

6. Ministry of Health of Republic of Indonesia(a). Recommended Dietary Allowance of Indonesian Population, 2013.

7. Rolls E.T. Taste, Olfactory and Food-texture Processing in the Brain and the Control of Appetite, in Obesity Prevention. San Diego: Academic Press2010;41-56.

8. Kearney J. Food consumption trends and drivers. Phil Trans $R$ Soc B2010;365:2793-2807.

9. Ledikwe JH, Blanck HM, Kettel Khan L et al. Dierary energy density is associated with energy intake and weight status in US adults. Am J Clin Nutr2006;83(6):1362-1368.

10. Johnson L, Mander AP, Jones LR et al. Energy-dense, low-fiber, high-fat dietary pattern is associated with increased fatness in childhood. Am J Clin Nutr2008;87(4):846-854.

11. Rolls BJ, Drewnowski A, Ledikwe JH. Changing The Energy Density of The Diet as a Strategy For Weight Management. J Am Diet Assoc2005;105(5 Suppl 1):98-103.

12. Erhardt J. Nutrisurvey for Windows. SEAMEO-TROPMED-RCCNUniversity of Indonesia: Indonesia,2007.
13. Rolls B. Energy Density and Nutrition in Weight Control Management. The Permanente Journal2003;7(2):28-30.

14. Duffey K, Popkin B. Energy Density, Portion Size, and Eating Occasions: Contributions To Increased Energy Intake in the United States, 1977 2006. Plos Medicine.2011;8(6):1-8.

15. World Cancer Research Fund (WCRF UK). ENERGY DENSITY : finding the balance for cancer prevention. 2012[online].

16. The National Agency of Drug and Food Control: Decree of the Head of the National Agency of Drug and Food Control, Food Labelling Recommendation;2007.

17. Ministry of Health of Republic of Indonesia(b). Academic paper for balance nutrition guideline. Jakarta: Director General of Nutrition \& Maternal and Child Health-MOH RI, 2013.

18.American Institute for Cancer Research (AICR). Food, Nutrition, Physical Activity, and the prevention of cancer : a Global perspective. Washington DC: World Cancer Research Fund International,2007.

19. Rolls BJ.Plenary Lecture 1: Dietary Strategies for the Prevention and Treatment of Obesity. Proc Nutr Soc2010;69(1):70-79.

20. Catharina Y.W. Ang, Keshun Liu, Yao-Wen Huang. Asian food: science and technology. Lancaster, Pennsylvania:CRC Press,1999.

21. Barbara J Rolls, Liane S Roe, Jennifer S Meengs J. Portion size can be used strategically to increase vegetables consumption in adults. $\mathrm{Am} J$ Clin Nutr2010;91(4):913-922.

22. Ledikwe JH, Ello-Martin JA, Rolls BJ. Porsion size and the obesity epidemic.J Nutr2005;135(4):905-909.

23. Ello-Martin JA, Roe LS, Ledikwe JH et al. Dietary energy density in the treatment of obesity; a year-log trial comparing 2 weight-loss diet. $\mathrm{Am}$ J Clin Nutr2007;85(6)1465-1477.

24. Rizki D, Munandar J, Andrianto M. Analisis Persepsi Konsumen dan Strategi Pemasaran Beras Analog (Analog rice). Jurnal Manajemen dan Organisasi2013;4(2):144-162.

25. Drewnowski A, Specor S. Poverty and obesity: the role of energy density ad energy costs. Am J Clin Nutr2004;79(1):6-16. 